\title{
Pengolahan Air Asam Tambang di Penambangan Mineral Logam Kabupaten Pacitan Provinsi Jatim dengan Metoda Elektrokoagulasi
}

\author{
Radhitya Adzan Hidayah' ${ }^{*}$, Heru Dwiriawan Sutoyo², Nurul Dzakiya', Yoga Ady Saputra \\ ${ }^{1}$ Teknik Geologi, IST AKPRIND YK, Indonesia \\ 2 Teknik Pertambangan, ITY, Indonesia
}

3 Teknik Elektro, IST AKPRIND YK, Indonesia

\section{ARTICLE INFO}

Riwayat Artikel:

Draft diterima: 23 November 2020

Revisi diterima: 11 Desember 2020

Diterima: 15 Desember 2020

Tersedia Online: 26 Desember 2020

${ }^{*}$ Corresponding author:

radhitya.adzan.h@akprind.ac.id

\begin{abstract}
ABSTRAK
Daerah Kabupaten Pacitan, areanya termasuk di dalam pegunungan selatan Jawa Timur, kaya akan kandungan mineral tembaga dan logam lainnya. Area berada di Kecamatan Ngadirojo, konsesi perusahaan PT.Gemilang Limpah Internusa, salah satu perusahaan yang bergerak di bidang industri pertambangan tembaga, dimana dalam produksinya menghasilkan Air Asam Tambang yang berpotensi mencemari sungai warga karena tambang ini terletak di hulu sungai. Menurut asal usul dan genesa, terbentuknya mineral logam, termasuk tembaga di dalamnya, terjadi karena proses hydrothermal di dalam permukaan bumi. Situasi ini yang menjadi sebab kegiatan eksploitasi terhadap mineral tersebut dan penyertanya menimbulkan adanya dampak perubahan kondisi lingkungan. Eksploitasi ataupun pengambilan material tersebut juga membuat kualitas dari air tanah sekitar memburuk. Saat ini perusahaan masih menggunakan metode cara lama, dengan menggunakan serbuk kapur tohor dalam mengikat polutan/limbah yang muncul. Metode elektrokoagulasi merupakan salah satu metode alternatif dalam mengelola air asam tambang, sehingga diharapkan tingkat kerusakan lingkungan dengan metode ini bisa menurunkan tingkat pencemaran dengan lebih baik. Dari beberapa percobaan, dengan waktu tertentu, semakin lama waktu aliran listrik, semakin baik tingkat penjernihan air asam tambang. Sehingga waktu yang diperlukan bisa dipercepat sebelum air masuk ke sungai. Elektrokoagulasi juga dapat sebagai alternative cara yang lebih efisien dan cepat untuk menetralkan air asam tambang selain dengan kapur tohor
\end{abstract}

Kata kunci:Kabupaten Pacitan, mineral logam, air asam tambang, elektrokoagulasi

\begin{abstract}
Pacitan Regency is one of the areas of East Java Province, which has metal mineral mining prospects. The area is located in Ngadirojo District, a company concession of PT.Gemilang Limpah Internusa, one of the companies engaged in the copper mining industry, produces Acid Mine Water, which has the potential to pollute the residents' rivers because the mine is located upstream of the river. Excavation is under the earth's surface; copper is no exception. This condition causes a tendency for copper mining operations and their association to be at risk of environmental change. The opening of mining areas, apart from having the potential to change the landscape, also has the potential to divert (lowered the quality) of water influx in the local area environment. Currently the company is still using a conventional method, namely by using quicklime to tie up the existing waste. The electrocoagulation method is an alternative method for managing acid mine drainage, so it is hoped that the level of environmental damage by this method can reduce the level of pollution better. From several experiments, with a certain time, the much longer the electricity flow time, the better of the purification level of acid mine drainage. So that the time needed can be accelerated before the water enters the river.
\end{abstract}




\section{PENDAHULUAN}

Daerah penelitian merupakan konsesi tambang basemetal milik PT. Gemilang Limpah Internusa, yang merupakan hulu sungai Ngadirojo, memiliki potensi air asam tambang yang cukup tinggi pada waktu musim penghujan (Gambar 1). Akibat air asam tambang yang cukup melimpah, belum sempat di treatment dengan cepat, sudah terburu masuk dalam aliran air sungai, sehingga mencemari tanaman warga hingga tanaman tersebut mati. Melihat dan mengukur kadar serta tingkat keasaman air terhadap aktivitas pembongkaran material dari dalam bumi (eksploitasi penambangan) menjadi sangatlah penting, dikarenakan air yang kandungannya relative asam akan menjadi sebab dan dampak persoalan yang timbul setelah kegiatan penambangan di lakukan. Dampak maupun permasalahan yang nanti akan muncul sebagai dampak kegiatan eksploitasi mineral memerlukan penanggulangan yang baik, agar tidak mengakibatkan pencemaran lingkungan, yang mana sungai sebagai salah satu agen transportasi tempat air dari penambangan disalurkan, masih merupakan sumber utama air masyarakat, dalam pemanfaatanya sehari-hari dipakai sebagai media penyiraman kebun, dan tanaman seperti padi, dan lain sebagainya.

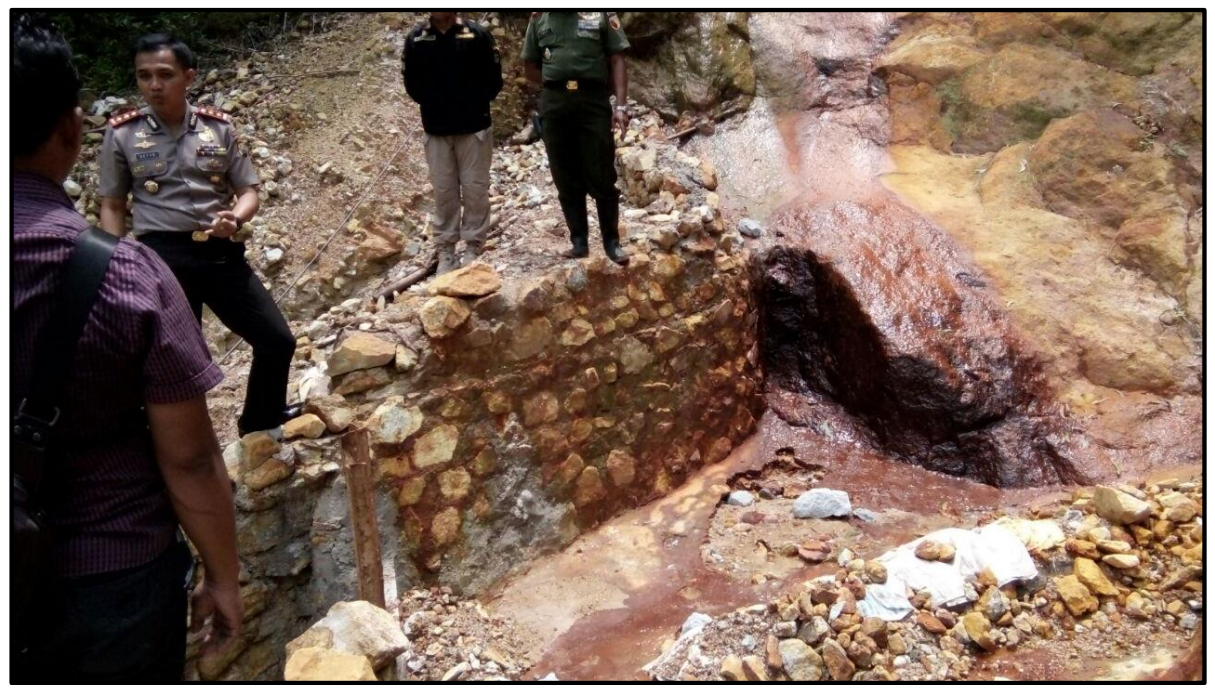

Gambar 1. Pencemaran Limbah air asam tambang, berwarna merah kecoklatan di area pemukiman penduduk, sempat dilakukan sidak oleh pejabat terkait

Dalam proses kimiawi jika overburden/tanah penutup yang dibongkar mengandung komposisi mineral sulfida berinteraksi dengan oksigen dan air, baik air permukaan maupun bawah permukaan, proses tersebut akan mendukung terjadinya pembentukan Air Asam Tambang (AAT / Acid Mine Drainage / AMD)[1] . Komposisi bakteri yang secara alamiah terbentuk di dalam air asam tambang muncul bakteri Thiobacillus ferooksidans[2] yang berperan menjadi katalis pembentukan air asam tambang[1]. Air asam tambang yang sudah terjadi proses reaksi kimia menyebabkan dampak pengaruh buruk terhadap kualitas air dan tanahnya, karena $\mathrm{pH}$ air dan tanah di area dimaksud menurun cepat. Pada air asam tambang, $\mathrm{pH}$ tanah yang sangat rendah dipastikan akan menyebabkan gangguan dari keseimbangan unsur hara penting di wilayah tersebut. Karena sifat dasar air asam tambang akan menambah kecepatan larutnya mineral logam berat di lingkungan sekitar penambangan. Dalam situasi wilayah lingkungan dengan $\mathrm{pH}$ rendah akan mengurangi unsur hara makro, karena diikatnya unsur hara oleh logam dan terjadi peningkatan kelarutan unsur hara mikro secara bersamaan[3].

Adapun akibat lainnya dari air asam tambang ini di antaranya adalah peralatan perusahaan pertambangan mengalami percepatan korosif yang berbahan baja atau besi sehingga dampak kerusakan peralatan semakin cepat, yang semakin menambah kesulitan finasial dari perusahaan. Pada lingkungan biodiversity, efek terburuk dari AAT ini adalah rusaknya populasi fauna juga flora yang terjadi di lokasi bekas ekploitasi pertambangan serta sebaran populasi kehidupan di daerah aliran sungai (das) yang dilewati oleh air asam tambang ini baik secara langsung ataupun tidak langsung. Proses ini akan berakibat terhadap kualitas air yang berada di konsesi pertambangan berdampak mempengaruhi kesehatan manusia. Dampak lain yang ditimbulkan oleh AAT yaitu bertambahna faktor kesulitan disaat perusahaan akan melakukan kegiatan penanaman kembali/reklamasi daerah bekas tambang karena kualitas air dan tanah yang sangat asam terhadap tumbuhan untuk berkembang[1].

Pengolahan air asam tambang dengan metode konvensional telah diterapkan pada saat awal produksi berlangsung oleh perusahaan (Gambar 2). Menggunakan dua sistem pengolahan yaitu pengolahan secara preventif dan pengelolaan secara kuratif. Pengolahan secara kuratif dilakukan pada AAT yang telah terbentuk sebagai air permukaan. Pengelohan secara kuratif terdiri dari dua metode yaitu metode pasif (passive treatment) dan metode aktif (active treatment). Metode aktif merupakan pengolahan dan reduksi efek AAT dengan menambahkan serbuk kimia untuk dalam usaha memperbaiki kualitasnya. Pengolahan selanjutnya 
dilakukan dengan maksud mengendapkan unsur yang terkandung di dalam AAT. Metode yang dilakukan dengan dua cara, pertama menambahkan kapur tohor $(\mathrm{CaO})$ atau batu kapur $(\mathrm{CaCO})$ pada AAT yang berasal langsung dari underground mine (tambang bawah tanah), bertujuan menaikan pH AAT dilain pihak akan membuat keruh air tersebut serta dilakukan dengan membuat beberapa kolam pengendapan (settling pond) yang saling terhubung antar masing-masing kolam[3] pada Gambar 3. Aplikasi teknologi elektrokoagulasi sangat cocok dipakai dalam pengolahan air asam tambang karena flokulan yang dihasilkan hanya berasal dari air asam tambang dari lokasi penambangan bawah tanah tanpa adanya masukan lain ataupun material koagulan dari luar, sangat minimnya potensi pencemaran limbah dari cecernya bahan kimia saat disimpan atau pada waktu distribusi bahan kimia ke wilayah pengolahan limbah cair tersebut[1].

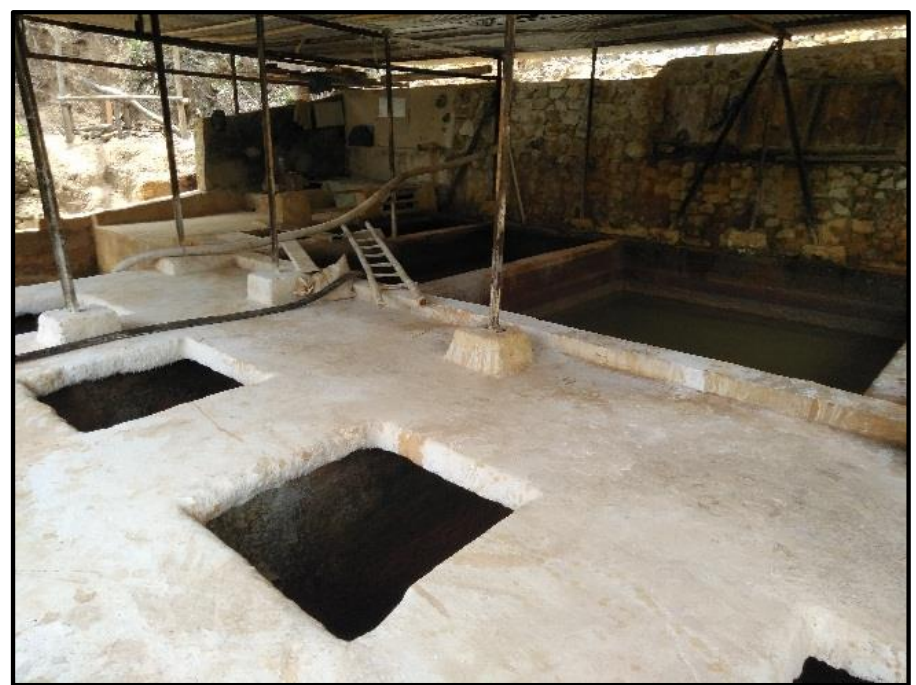

Gambar 2. Pengolahan air asam tambang perusahaan dengan mencampur dengan kapur tohor

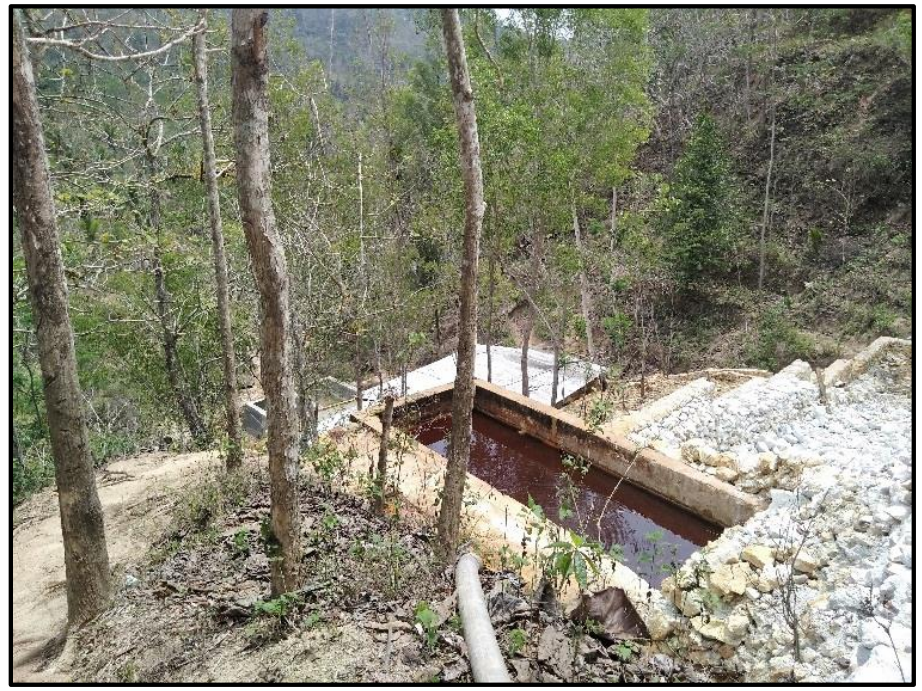

Gambar 3. Kolam pengendapan pertama (settling pond) setelah air keluar dari tambang dalam (underground mine)

\section{METODE PENELITIAN}

\section{Peralatan \& Bahan Uji}

Teknologi perancangan alat untuk penerapan elektrokoagulasi sederhana untuk pengolahan limbah pertambangan mineral logam tembaga skala Laboratorium, Air Asam Tambang (AAT) yang diambil sampelnya dari eksploitasi pertambangan mineral logam dasar dan tembaga PT. Gemilang Limpah Internusa. Prinsip dan metode kerja dari metode ini dipakai 2 buah lempeng pipih elektroda berbentuk persegi panjang, terdiri dari 1 lempengan besi bentuk kotak sebagai katoda dan 1 lempeng aluminium bentuk kotak sebagai anoda. masing-masing elektroda mempunyai panjang $11 \mathrm{~cm}$, tinggi $8 \mathrm{~cm}$ dan ketebalan $0,8 \mathrm{~cm}$. Dua buah lempeng ini diinstalasi ke dalam bejana 
akuarium kaca yang berfungsi sebagai mini reactor (Gambar 4a), tempat berlangsungnya reaksi elektrokoagulasi. Bejana ini memiliki panjang $15 \mathrm{~cm}$, lebar $15 \mathrm{~cm}$ dan tinggi $25 \mathrm{~cm}$, berasal dari bahan kaca tembus pandang dengan ketebalan $0.5 \mathrm{~cm}$. Dalam melengkapi proses dan kinerja elektroagulasi dirakit sebuah adaptor portabel (Gambar 4b) untuk memodifikasi waktu aliran listrik dan arus listrik untuk mengetahui seberapa besar tingkat efektivitas dari proses elektrokoagulasi [4]. Air asam tambang diambil dari kolam (settling pond) yang kedua. Air asam tambang muncul dari kegiatan penambangan dalam, karena memotong muka air tanah. Air dimasukkan ke dalam botol, selanjutnya dibawa untuk dianalisis unsur pH dan kekeruhannya di Laboratorium Teknik Lingkungan, IST AKPRIND. Parameter yang diuji ditahapan awal ini adalah kekeruhan, pH dan kandungan Fe nya.
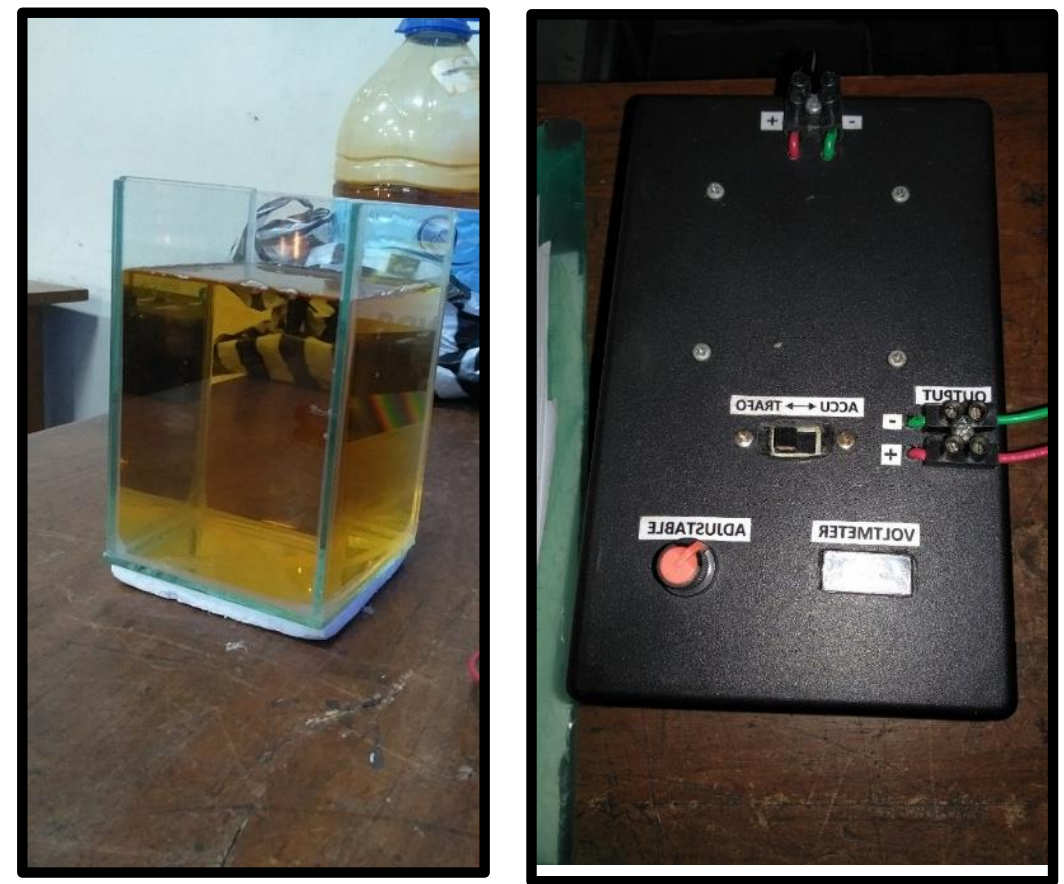

Gambar 4. (a) Bejana kaca dan (b) adaptor travo, untuk memodifikasi arus dan voltase listrik

\section{HASIL DAN PEMBAHASAN}

Perlakuan khusus terhadap air asam tambang adalah hal yang perlu diterapkan selama aktivitas eksploitasi berlangsung dan paska eksploitasi berakhir. Air asam tambang (Acid Mine Drainage) berpengaruh langsung terhadap turunnya kualitas tanah beserta air permukaan. Apabila terjadi limpasan/overflow di kolam pengendapan air asam karena curah hujan yang tinggi, yang kemudian masuk ke dalam aliran sungai, menyebabkan dampak yang buruk terhadap masyarakat yang berada di daerah aliran sungai serta akan mempengaruhi populasi biota yang berada di darat juga biota sungai. Hilir dari sungai Ngadirojo, merupakan area persawahan dan pemukiman yang padat penduduknya, sehingga pengolahan air asam tambang harus dilakukan dengan baik.

\section{Perlakuan}

Sampel air limbah diambil dari area pertambangan bawah tanah, kemudian proses elektrokoagulasi dilakukan untuk mengetahui dan menentukan pada tingkat berapa efektifitas yang paling baik untuk tegangan listrik DC yang diperlukan[5,6], serta waktu proses elektrokoagulasi yang terjadi di dalam air asam tambang konsesi PT. GLI. Bejana kaca diisi dengan air asam tambang sebanyak $600 \mathrm{Ml}$, kemudian elektroda diberi arus listrik searah dengan menggunakan tegangan sesuai data yang telah ditetapkan untuk penelitian ini, selain waktu yang telah ditetapkan sehingga terjadilah proses elektrokimia di dalam air asam tambang tersebut yang menyebabkan kation bergerak menuju katoda ${ }^{9}$ dan anion bergerak menuju anoda. Pada akhirnya akan terbentuk flokulanflokulan terapung dan tenggelam yang berasal dari partikel-partikel di dalam air asam tambang yang mengalami reaksi tersebut[7,8] . 
Sampel air asam tambang diuji dengan elektrokoagulasi dengan 2 macam nilai tegangan yang berbeda (Gambar 5), yang pertama dengan 3 volt, kedua dengan 6 volt. Dari hasil percobaan tegangan 3 volt membutuhan waktu 1,5 jam agar air asam tambang menjadi jernih, flokulan mengapung, sedangkan volt 6 meter membutuhkan waktu hanya sekitar 45 menit untuk menjernihkan air asam tambang (secara visual). Dari percobaan di atas menunjukkan semakin tinggi voltase maka akan semakin cepat waktu dipakai untuk menetralkan air asam tambang, sehingga sangat efisien dalam mempercepat waktu pengolahan.

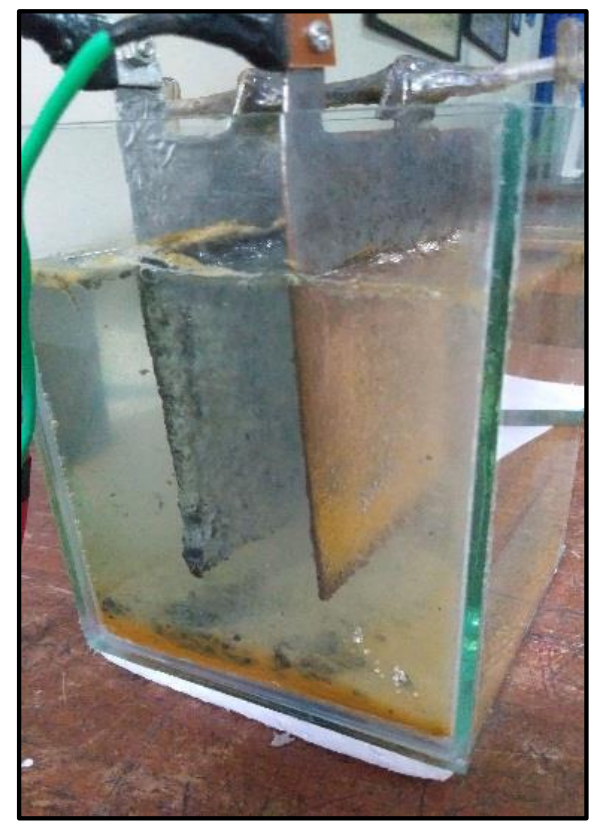

Gambar 5. Air asam tambang setelah melewati bebarapa kali percobaan, pada percobaan ke dua tampak air secara visual telah jernih dan terjadi pengendapan logam berat pada dasar bejana, waktu lebih cepat linear dengan voltase

\section{KESIMPULAN}

Dari hasil data yang didapatkan, terindikasi air asam tambang di lokasi perlu dilakukan treatment yang lebih efektif dengan metode elektrokoagulasi. Walaupun belum dilakukan analisis kimia paska elektrokoagulasi, dari pengamatan visual Nampak perubahan warna dan air menjadi lebih jernih. Semakin tinggi nilai voltase makan akan semakin mempercepat proses treatment dari air asam di daerah penelitian. Sehingga metode kapur tohor yang selama ini dipakai bisa diganti dengan metode elektrokoagulasi, yang secara aktif bisa mempercepat proses penjernihan air sebelum masuk ke sungai, mengingat pada musim penghujan, debit air akan lebih besar. Beberapa perbaikan untuk kemajuan penelitian yang akan datang, agar bisa dirancang berapa besar efektifitas alat sesuai dengan debit air asam tambang serta arus listrik yang dipakai, mengingat di lokasi harus menggunakan genset.

\section{UCAPAN TERIMAKASIH}

Ucapan terima kasih sebesar-besarnya dihaturkan kepada manajemen PT. Gemilang Limpah internusa atas ijin akses masuk dan mengambil data lapangan, kedua kepada dinas dan instansi daerah, laboratorium Teknik Lingkungan IST AKPRIND, dan semua pihak yang telah membantu dalam penelitian ini.

\section{REFERENSI}

[1] Ashari, D. Budianta, D. Setiabudidaya, "Efektivitas Elektroda pada Proses Elektrokoagulasi untuk Pengolahan Air Asam Tambang”, Jurnal Penelitian Sains Volume 17 Nomor 2, Mei 2015.

[2] K. Thirugnanasambandham, V. Sivakumar, J.P. Maran, "Optimization of Electrocoagulation Process to Great Biologically Pretreated Bagasse Effluent", Journal of the Serbian Chemical Society, 78: 613-626, 2013.

[3] N. Ita, Nurhasni, Z. Salimin "Pengolahan Limbah Industri Elektroplating dengan Proses Koagulasi Flokulasi," 306-311, Prosiding Semirata FMIPA Universitas Lampung, Lampung. 2013.

[4] Prayitno, E. Kismolo, Percobaan Awal Proses Elektrokoagulasi sebagai Metode Alternatif Pada Pengolahan Limbah Cair. 
Pusat Teknologi Akselerator, Yogyakarta 2012.

[5] T.R. Rude, Short Course Acid Mine Drainage; Causes and Management, Institut of Hydrogeology RWTH Aachen, Aachen, 2017 [6] Sipahutar, Renni, Analisis Pengelolaan Limbah Air Asam Tambang Di lup Tambang Air Laya Pt. Bukit Asam (Persero), Tbk. Unit Pertambangan Tanjung Enim, UNSRI. Indralaya, 2013.

[7] Sutanto, “Penurunan Kadar Logam Berat dan Kekeruhan Air Limbah Menggunakan Proses Elektrokoagulasi”, Jurnal Ilmiah Elite Elektro, Jakarta, 2011.

[8] B. Rachmawati, Y. Surya, M. Mirwan. "Proses Elektrokoagulasi Pengolahan Limbah Laundry". Jurnal Ilmiah Teknik Lingkungan, 6: 15-22, 2014. 